\title{
Effect of in feed administration of different butyrate formulations on Salmonella Enteritidis colonization and cecal microbiota in broilers
}

\author{
Lonneke Onrust ${ }^{1}$, Steve Baeyen ${ }^{2}$, Freddy Haesebrouck ${ }^{1}$, Richard Ducatelle ${ }^{1}$ and Filip Van Immerseel ${ }^{*}$
}

\begin{abstract}
Butyrate has been used extensively as a feed additive to improve gut health and to decrease Salmonella colonization in poultry. Salmonella mainly colonizes the ceca so butyrate concentrations should be increased in this gut segment. Discrepancies on the effects of butyrate on Salmonella colonization, described in the scientific literature, could thus be due to butyrate release location effects. In this study, newly developed butyrate formulations were evaluated for their effect on cecal butyrate concentrations and on colonization by Salmonella Enteritidis. In a first trial, broilers were randomly allocated to 7 dietary treatment groups with formulations based on different approaches to modify the butyrate release profile: release from wax matrices based on diffusion/erosion; micropellets supposedly release butyrate around $\mathrm{pH} 7$ in the colon; tributyrin is based on the hydrolysis of esters in the small intestine. Fat-protected butyrate was included as a reference, because of its known effect on reduction of Salmonella colonization. Four days after infection, the number of cfu Salmonella per g cecal content and spleen were determined. Butyrate formulations in a wax matrix significantly reduced the Salmonella colonization in cecal content. In a second trial, wax and fat-protected butyrate treatments were replicated and results from the first trial were confirmed. Compared to the control group a higher proportion of butyrate concentration was observed in ceca for those groups with reduced Salmonella colonization. This was associated with a beneficial shift in the cecal microbiota. In conclusion, formulations that increase cecal butyrate concentrations are superior in protecting against Salmonella Enteritidis colonization.
\end{abstract}

\section{Introduction}

Despite years of strict monitoring and control in production animals worldwide, Salmonella is still a major foodderived zoonotic pathogen for humans. Poultry meat and eggs, as well as processed products thereof, still are the main sources of Salmonella infections in man $[1,2]$. The most important Salmonella serotype associated with consumption of poultry products is Salmonella Enteritidis, which has been reported in more than half of the outbreaks in Europe in 2016 [1,3]. This serotype causes

\footnotetext{
*Correspondence: filip.vanimmerseel@ugent.be

1 Department of Pathology, Bacteriology and Avian Diseases,

Faculty of Veterinary Medicine, Ghent University, Salisburylaan 133, 9820 Merelbeke, Belgium

Full list of author information is available at the end of the article
}

egg-derived human infections, and is the consequence of systemic spread to the avian reproductive tract, resulting in internal egg contamination [4]. Poultry meat can be contaminated by a variety of serotypes, all colonizing the intestinal tract of broilers, such as serogroup $C$ strains (e.g. Infantis), but also Typhimurium and Enteritidis. While in layers and breeders vaccination has been successful in reducing Salmonella Enteritidis, one is still in need for an efficient strategy to reduce gut colonization levels in broilers.

Effects of short chain fatty acids (SCFA), especially butyrate, on gastrointestinal function of animals have been widely studied over the past years [5-8]. Guilloteau et al. give an overview of the favorable effects of butyrate on the gastrointestinal tract (GIT) of broilers, including stimulation of growth performance, anti-inflammatory

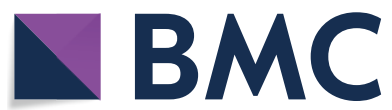

(c) The Author(s) 2020. This article is licensed under a Creative Commons Attribution 4.0 International License, which permits use, sharing, adaptation, distribution and reproduction in any medium or format, as long as you give appropriate credit to the original author(s) and the source, provide a link to the Creative Commons licence, and indicate if changes were made. The images or other third party material in this article are included in the article's Creative Commons licence, unless indicated otherwise in a credit line to the material. If material is not included in the article's Creative Commons licence and your intended use is not permitted by statutory regulation or exceeds the permitted use, you will need to obtain permission directly from the copyright holder. To view a copy of this licence, visit http://creativeco mmons.org/licenses/by/4.0/. The Creative Commons Public Domain Dedication waiver (http://creativecommons.org/publicdomain/ zero/1.0/) applies to the data made available in this article, unless otherwise stated in a credit line to the data. 
effects, maintenance of intestinal epithelial barrier integrity, and reduction of Salmonella colonization [9]. Butyrate has been extensively used as a feed additive to decrease Salmonella colonization in poultry in experimental models and in the field. The results, however, are not always consistent. In addition to factors such as inclusion level, diet composition, age, and health status, release locations of butyrate may partly explain the inconsistent effects of butyrate on Salmonella colonization [6]. Decreased intestinal Salmonella colonization and shedding was shown using in-feed coated butyric acid supplements, but not using uncoated butyric acid supplements $[7,10,11]$, pointing to formulation effects. Unprotected butyrate is readily absorbed in the upper GIT and will not reach the ceca [12]. The ceca are the preferred colonization site of Salmonella and thus butyrate formulations should preferably increase butyrate concentrations in this segment $[5,7,9]$. It is striking that no studies have been published yet to determine cecal butyrate concentrations after application of in-feed butyrate supplements. Previous in vitro research has shown distinctive release profiles of newly developed and commercially available butyrate formulations, produced using different encapsulation techniques [13]. A commonly used technique is embedding butyrate in vegetable fat matrices resulting in sustained release of butyrate in the broiler GIT [14]. One of the newly developed formulations for sustained release of drugs contains a food-grade petroleum-derived wax as embedding material [14]. This technique is used in the pharmaceutical industry and shows a sustained release of butyrate in vitro $[13,15]$. Direct comparisons between these formulations with respect to their effects on Salmonella colonization have not yet been performed.

Therefore, the purpose of the present study was to evaluate the effect of different butyrate formulations on Salmonella Enteritidis colonization and shedding, on the SCFA concentration in ceca, and on the cecal microbiota composition in broilers.

\section{Materials and methods Butyrate derivatives}

Novel butyrate derivatives were developed using different pharmaceutical technologies to produce formulations with different release patterns of butyric acid in the GIT of broilers. The first formulation consisted of a microcrystalline wax (Lunacera $\mathrm{M}$ wax beads, Füller $\mathrm{GmbH}$, Lüneburg, Germany) and sodium butyrate (Adimix C, Nutri-Ad International NV, Dendermonde, Belgium), henceforth called Wax (resp. 70\%/30\% w/w). The second formulation included, in addition to the aforementioned components, S2004 soluble potato starch in dry powder form (Sigma-Aldrich, Saint-Louis, USA), hereafter called Wax $+($ resp. $60 \% / 30 \% / 10 \% \mathrm{w} / \mathrm{w})$. As described by Moquet [13], melt-extrusion and grinding were used to produce matrices of microcrystalline wax containing sodium butyrate. Prior to mixing, wax beads were ground at $15000 \mathrm{rpm}$ with a ZM-1000 grinder (Retsch, Haan, Germany) equipped with a 12-tooth rotor, and without screen. Each formulation was mixed with a pedal mixer model 305 (Dinissen, Sevenum, The Netherlands) at $50 \%$ of the maximum speed for $5 \mathrm{~min}$ and subsequently extruded with a Baker-Perkins twin screw extruder. Extrusion settings were adjusted for each formulation in order to obtain homogenous, smooth-surfaced, nonmelted extrudates [12]. Extrudates were cooled down to room temperature overnight and subsequently ground at $10000 \mathrm{rpm}$ with a ZM-1000 grinder (Retsch) equipped with a 12-tooth rotor without screen. Ground extrudates were sieved to obtain the $0.8-1.2 \mathrm{~mm}$ fraction (Figure 1).

A third novel butyrate formulation was developed by wet-extrusion, spheronization and fluidized-bed reactor coating, resulting in microencapsulated pellets containing butyrate with a $\mathrm{pH}$-sensitive polymer, from now on called micropellets. Moquet [13] described the workflow of the production, which consisted of mixing microcrystalline cellulose (Avicel PH-101; $850 \mathrm{~g} / \mathrm{kg}$; FMC BioPolymer, Philadelphia, USA) [16] and sodium butyrate (150 g/ kg; Admix C, Nutri-Ad International NV) (resp. 70\%/30\% $\mathrm{w} / \mathrm{w}$ ), and adding demineralized water in a drop-wise manner while mixing. The resulting wet mixture was extruded with a dome granulator model DG-L1 (FujiPaudal, Osaka, Japan) and spheronized for 5 min (spheronizer model 15, Sturminster Newton, UK). The obtained pellets were dried overnight at room temperature and sieved afterwards to select the $0.8-1.2 \mathrm{~mm}$ fraction. A fluidized-bed reactor model GPCG1 (Glatt GmbH, Binzen, Germany) including a Wurster module was used to coat the pellets with Eudragit ${ }^{\circledR}$ FS 30 D (Evonik Industries, Essen, Germany), a copolymer based on methyl acrylate, methyl methylacrylate and methacrylic acid that dissolves at $\mathrm{pH}$ higher than 7 (Figure 1).

In this study, these novel butyrate derivatives were tested in parallel with a commercially available fat-protected butyrate (Adimix Precision, Nutri-ad International $\mathrm{NV}$ ), non-protected sodium butyrate (Adimix C, Nutriad International NV), and tributyrin (T8626, SigmaAldrich). The formulations were based on different approaches to modify butyrate release profile by either sustained release or targeted release. Sustained release refers to the prolonged release of an active compound over time based on enzymatic or mechanic erosion and diffusion mechanisms [13]. Release from wax matrices is based on diffusion/erosion and is nearly $\mathrm{pH}$ independent. As the active compound butyrate has been embedded in the matrix (wax), no distinction can be made between an inner and outer shell. Addition of starch to the wax 


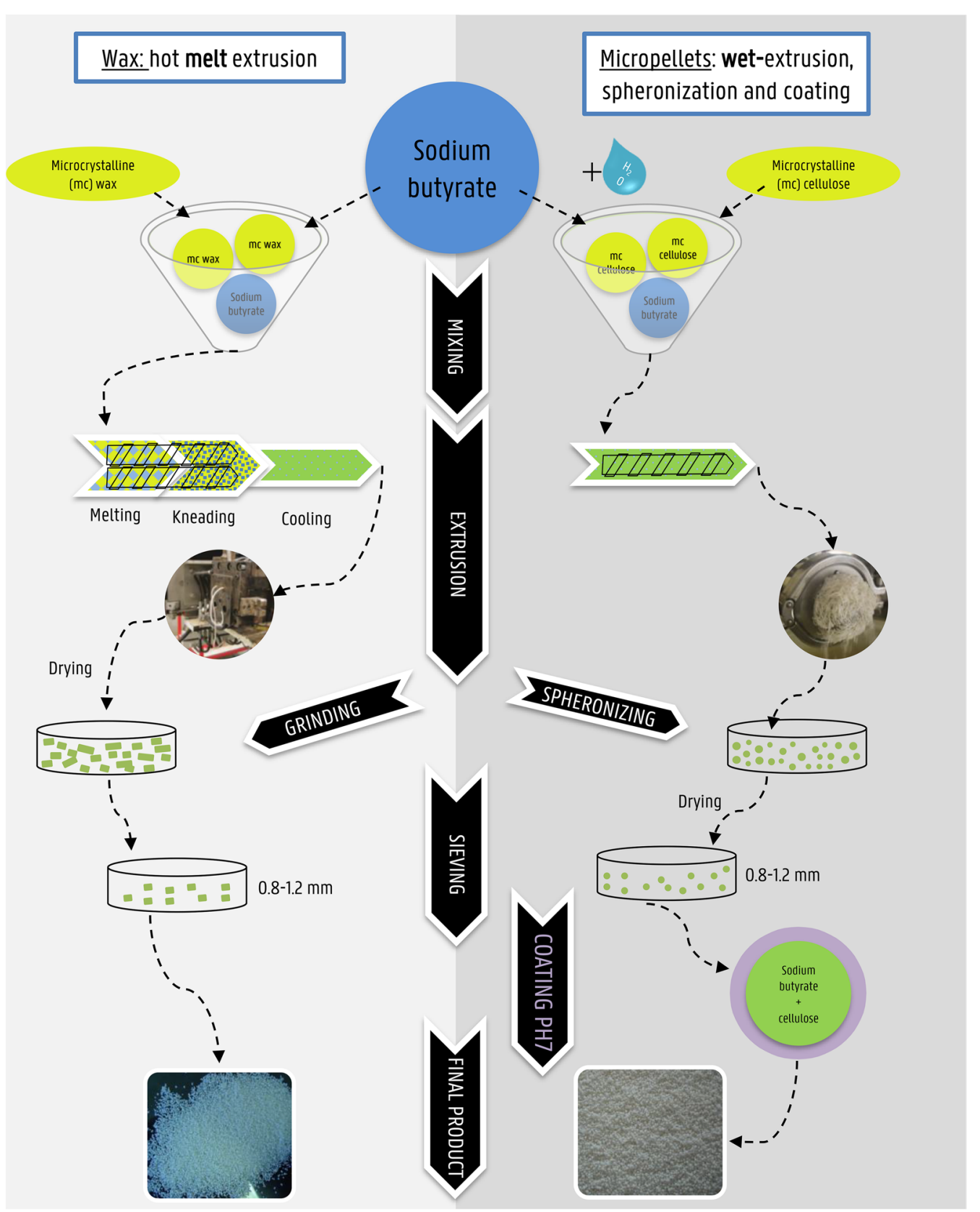

Figure 1 Workflow production process novel butyrate formulations [Right] Production process of wax by using hot melt extrusion, resulting in a wax matrix carrying the active pharmaceutical ingredient sodium butyrate. To obtain wax + with the addition of starch, soluble potato starch in dry powder form was added during the mixing step. [Left] Production process of micropellets using wet-extrusion, spheronization and applying a pH-dependent coating. Final product is sodium butyrate with cellulose protected by an additional layer (purple sphere).

was used as a disintegrant, making the matrix less sustainable compared to wax and influencing the release rate of butyrate [15]. Targeted release refers to localized delivery of the active compound based on organ-specific characteristics such as $\mathrm{pH}$ value or enzymatic activity [13]. For the micropellets a distinction can be made between an inner and outer shell, with the outer shell a
$\mathrm{pH}$ sensitive polymer resistant against $\mathrm{pH}$ values lower than 7, and the inner shell containing the active compound butyrate. As the $\mathrm{pH}$ increases throughout the GIT in broilers, the micropellets supposedly release butyrate around $\mathrm{pH} 7$ in colon [17]. Endogenous lipases are able to cleave ester bonds of tributyrin at the first and third position of the glycerol backbone [18]. As chickens have a low 
pre-duodenal lipolytic activity, it is assumed that butyric acid will mostly be hydrolyzed in duodenum/jejunum by pancreatic lipases [19]. The fat-protected butyrate was included as a reference, because of its known effect on reduction of Salmonella colonization [7].

\section{Bacterial strain}

Salmonella enterica serotype Enteritidis phage type 4 strain 147, a well characterized streptomycin resistant strain, was used in the experiments. This strain was originally isolated from egg white and has been shown to have a high capacity of colonizing the gut and internal organs in chickens [20]. The strain was grown for $6 \mathrm{~h}$ in LuriaBertoni medium (LB, Sigma, St. Louis, MO, USA), after which the number of CFU (colony-forming unit) per gram was determined by plating 10 -fold dilutions of the bacterial suspension on xylose lysine deoxycholate agar (XLD, Oxoid, Basingstoke, UK). The bacterial suspension was stored at $4{ }^{\circ} \mathrm{C}$ during plate counting and was diluted in Phosphate-buffered saline (PBS) to obtain the desired infection dose.

\section{Experimental design and diet}

In a first experiment, 140-day-old male chicks were divided in 7 pens of 20 animals, assigned to 7 different dietary treatment groups. Included dietary treatments groups were given feed containing commercially available fat-protected butyrate, non-protected sodium butyrate, and the novel butyrate derivatives, i.e. wax, wax + , micropellets or tributyrin. A control group receiving non-supplemented feed was also included.

In the second experiment, only the dietary treatments which significantly reduced Salmonella colonization in cecum during the first trial were tested to confirm the effect on colonization. 120-day-old male chickens were divided in 6 pens of 20 animals, assigned to 3 different dietary treatment groups: non-supplemented feed, wax and commercially available fat-protected butyrate.

All feed additives were mixed in commercially available broiler feed (Versele-Laga, Deinze, Belgium) at a concentration of $3 \mathrm{~g} / \mathrm{kg}$ of sodium butyrate. The experiments were approved by the ethical committee of the Faculty of Veterinary Medicine, Ghent University (EC 2014/135 and EC2015/46).

\section{Animals and experimental procedures}

Day-old Ross-308 chicks were obtained from a local hatchery, and randomly divided in pens of $1.44 \mathrm{~m}^{2}$ with solid walls and a solid floor covered with fresh wood shavings. Optimal temperature for broilers was maintained during the trial, and a light schedule of $18 \mathrm{~h}$ light $/ 6$ $\mathrm{h}$ darkness was applied. The birds had ad libitum access to water and feed. At 17 days post-hatch all chicks were orally inoculated with $10^{5} \mathrm{CFU}$ of Salmonella Enteritidis per bird. Cloacal swabs of all animals were taken the day before infection and at day 1 and 3 post-infection (dpi). At $4 \mathrm{dpi}$ all birds were euthanized, and samples from cecum and spleen were taken for bacteriological analysis. Additionally, intestinal content of cecum was collected for DNA extraction and 16S rRNA sequencing. Part of the cecal content was diluted 5 times in water, and afterwards homogenized and centrifuged $(2500 \times g, 10 \mathrm{~min})$ to obtain cecal water, for SCFA quantification.

\section{Sample processing and analysis}

Bacteriological analysis was performed as described by De Cort et al. [21]. Cloacal swabs were plated directly on XLD plates supplemented with $100 \mu \mathrm{g} / \mathrm{mL}$ streptomycin, and enriched in buffered peptone water (Oxoid, Basingstoke, UK) overnight at $37^{\circ} \mathrm{C} .1 \mathrm{~mL}$ of this suspension was enriched by brilliant green tetrathionate broth (Merck, Darmstadt, Germany) after which plating was performed on XLD with streptomycin. Cecal samples and spleens were mechanically homogenized in buffered peptone water. Ten-fold dilutions were made in Hank's Balanced Salt Solution (HBSS) and 6 droplets of $20 \mu \mathrm{L}$ of each dilution were plated on XLD plates supplemented with $100 \mu \mathrm{g} / \mathrm{mL}$ streptomycin. After incubation overnight at $37{ }^{\circ} \mathrm{C}$, the number of colonies was determined and numbers of CFU/g organ calculated. Samples that were negative after direct plating were enriched in buffered peptone water and brilliant green tetrathionate broth overnight at $37{ }^{\circ} \mathrm{C}$, followed by plating on XLD. When positive after enrichment these samples were presumed to have $83 \mathrm{CFU} / \mathrm{g}$ (detection limit of direct plating). Samples that were negative after enrichment were presumed to have $0 \mathrm{CFU} / \mathrm{g}$.

\section{SCFA quantification}

Quantification of SCFA in cecal water was done by the method previously described by De Weirdt et al. [22]. In short, butyrate, propionate and acetate were extracted from the samples using diethylether. Extracts with methyl hexanoic acid 99\% (Sigma-Aldrich) added as internal standard were analyzed on a gas chromatograph coupled with a flame-ionization detector and a split injector.

\section{DNA extraction}

For the extraction of DNA from the pellets obtained from the cecal contents the CTAB (cetyl trimethylammonium bromide) method described by Griffiths et al. [23] and Kowalchuk et al. [24] was used. $100 \mathrm{mg}$ of cecal content or $100 \mathrm{mg}$ of the obtained pellets was homogenized with $0.5 \mathrm{~mL}$ CTAB buffer (hexadecyltrimethylammonium bromide $>98 \%$ (Sigma Aldrich) 5\% (w/v), $0.35 \mathrm{M} \mathrm{NaCl}, 120$ $\mathrm{nM}$ K2HPO4) and $0.5 \mathrm{~mL}$ phenol-chloroform-isoamyl 
alcohol (25:24:1) (Sigma Aldrich) in destruction tubes. After homogenization, the samples were shaken 6 times for $30 \mathrm{~s}$ using a beadbeater (MagnaLyser, Roche, Basel, Switzerland) at $6000 \times g$ with $30 \mathrm{~s}$ in between shakings. The samples were centrifuged for $10 \mathrm{~min}$ at $8000 \times g$ and $300 \mu \mathrm{L}$ of the supernatant was transferred to a new tube. Re-extraction was done with an additional $250 \mu \mathrm{L} \mathrm{CTAB}$ buffer. The samples were homogenized and centrifuged again for $10 \mathrm{~min}$ at $8000 \times g$ and $300 \mu \mathrm{L}$ of supernatant was added to the first $300 \mu \mathrm{L}$. Phenol was removed by adding an equal volume of chloroform-isoamyl alcohol (24:1) (Sigma-Aldrich). The aqueous phase was transferred to a new Eppendorf tube. Nucleic acids were precipitated with 2 volumes of PEG-6000 solution (polyethyleenglycol $30 \%(\mathrm{w} / \mathrm{v}), 1.6 \mathrm{M} \mathrm{NaCl})$. After $2 \mathrm{~h}$ at room temperature, a last centrifugation step was done for 20 min at $13000 \mathrm{~g}$. The obtained pellet was rinsed with $1 \mathrm{~mL}$ of ice-cold, $70 \%(\mathrm{v} / \mathrm{v})$ ethanol. After drying the pellet was resuspended in $100 \mu \mathrm{L}$ RNAse free water (VWR, Leuven, Belgium).

\section{S rRNA amplicon sequencing and processing}

The 16S rRNA sequencing was performed using MiSeq v2 technology $(2 \times 250 \mathrm{bp})$ from Illumina at the GenoToul Genomics and Transcriptomics facility (Auzeville, France). This method has been described in detail by Vermeulen et al. [25].

Briefly, the hypervariable $16 \mathrm{~S}$ rDNA V3-V4 region was targeted with PCR1F_460 (5'CTTTCCCTACAC GACGCTCTTCCGATCTACGGRAGGCAGCAG3') and PCR2R_460 (5'GGAGTTCAGACGTGTGCTCTT CCGATCTTACCAGGGTATCTAATCCT3') primers. After amplification and purification, single multiplexing was performed using a 6-bp index during a second PCR with 12 cycles. Those PCR products were again purified, and the quality and the fragment length were checked before being loaded onto an Illumina MiSeq cartridge according to the manufacturer's instructions (Illumina Inc., San Diego, CA, USA). Next, sequences were demultiplexed, trimmed, merged, filtered, and the resulting reads were clustered into Operational Taxonomic Units (OTUs) with an identity level of $97 \%$. Chimera removal was done before the sequences of individual samples were mapped back to the representative OTUs and converted to an OTU table. OTU tables of the $16 \mathrm{~S}$ rRNA amplicon sequencing were analyzed using the QIIME software package (v1.9.0) [26]. Bacterial OTU sequences representative for taxonomy were aligned to the Silva v119 database 97\% rep set. Rarefaction analysis was done using the "alpha_rarefaction.py" script and indicated that a sequencing depth of 10000 reads was sufficient to analyze the bacterial community in the cecal samples from broilers.

\section{Statistical analysis}

Statistical analysis was carried out with InVivoStat (Cambridge, UK), a statistical software package which uses $R$ as its statistics engine [27]. Model assumptions were checked by visual inspection of the residuals. Differences of the mean between dietary treatment groups were analyzed with each pen as experimental unit. The differences were considered statistically significant at $P \leq 0.05$.

Data of the bacteriological analysis and SCFA measurements of the first trial did not meet model assumption of one-way ANOVA. Non-parametric Kruskal-Wallis test was used to analyze the data. All pairwise differences between the treatments were assessed using Behrens Fisher tests [28]. The data of the bacteriological analysis of the second trial and the SCFA measurements were assessed by one-way ANOVA using the following model: $\mathrm{Y}_{i j}=\mu+\tau_{i}+\varepsilon_{i j}$, where $\mathrm{Y}_{\mathrm{ij}}$ represents the $j$ th replicate $(j$ is 1-6) for the $i$ th treatment ( $i=$ control, wax or fat-protected butyrate). $\mu$ is the overall mean response, $\tau_{\mathrm{i}}$ is the $i$ th treatment effect, and $\varepsilon_{i j}$ is the random error associated with the $j$ th replicate fed the $i$ th treatment.

For data analysis of the $16 \mathrm{~S}$ sequencing, the OTU tables were normalized by removing those OTUs with an abundance lower than $0.01 \%$ in all samples. Multivariate analysis was done using the specific $R$ package Vegan (version 2.0-10) [29]. Dissimilarity matrices (based on the BrayCurtis dissimilarity index) were calculated from the OTU tables. Beta-diversity of the bacterial communities was studied by doing a Permutational multivariate analysis of variance (PERMANOVA) and a principal coordinate analysis (PCoA) on these dissimilarity indices.

To determine statistical differences in relative abundances of the bacterial families, non-parametric KruskalWallis test was used to analyze the data (InVivoStat, Cambridge, UK).

\section{Results}

First trial: effects on Salmonella colonization

All cloacal swabs taken before infection were negative for Salmonella. One and 3 days post-infection $75 \%$ of the broilers in the control group had positive cloacal swabs. After 1 dpi 4 of the 6 dietary treatments with a butyrate derivative resulted in significantly lower numbers of animals shedding Salmonella, compared to the control group. Only the treatment tributyrin resulted in a significantly lower number of positive cloacal swabs at $3 \mathrm{dpi}$ compared to the control group (Table 1).

Bacteriological analysis of cecum content after $4 \mathrm{dpi}$ showed that the dietary treatment group fed with the butyrate derivative wax resulted in a significantly reduced cecal colonization by Salmonella Enteritidis compared to the control group $(p=0.0006)$, to the groups fed a diet with unprotected sodium butyrate $(p=0.0018)$ and 
Table 1 Number of cloacal swabs positive for Salmonella Enteritidis strain 147 in the first trial

\begin{tabular}{llllllll}
\hline & \multicolumn{2}{l}{ Dietary treatment } & & & & \\
\cline { 2 - 7 } & Control & $\begin{array}{l}\text { Fat-protected } \\
\text { butyrate }\end{array}$ & $\begin{array}{l}\text { Uncoated } \\
\text { butyrate }\end{array}$ & Wax & Wax+ & Micropellets & Tributyrin \\
\hline $1 \mathrm{dpi}$ & $15 / 20$ & $6 / 19$ & $9 / 20$ & $2 / 19^{*}$ & $3 / 20^{*}$ & $4 / 20^{*}$ & $2 / 20^{*}$ \\
$3 \mathrm{dpi}$ & $15 / 20$ & $6 / 19$ & $11 / 20$ & $6 / 19$ & $7 / 20$ & $9 / 20$ & $2 / 20^{*}$ \\
\hline
\end{tabular}

Number of positive swabs on total per dietary treatment are given at 1 and 3 days post-infection (dpi) with $10^{5}$ CFU Salmonella. Broilers were fed a diet either or not supplemented with a butyrate containing feed additive in a concentration of $3 \mathrm{~g} / \mathrm{kg}$ of sodium butyrate.

* Significant difference in positive samples between control and dietary treatment with butyrate derivative $(p$-value $<0.05)$.

Table 2 Colonization of cecum and spleen by Salmonella Enteritidis strain 147 in the first trial

\begin{tabular}{lccccccc}
\hline & \multicolumn{1}{l}{ Dietary treatment } \\
\cline { 2 - 7 } & Control & Fat-protected butyrate & Uncoated butyrate & Wax & Wax+ & Micropellets & Tributyrin \\
\hline Mean cecum (SD) & $3.63^{\mathrm{a}}(1.27)$ & $2.56^{\mathrm{ab}}(1.63)$ & $3.45^{\mathrm{a}}(1.15)$ & $1.56^{\mathrm{b}}(1.75)$ & $2.87^{\mathrm{ab}}(2.25)$ & $3.87^{\mathrm{a}}(1.76)$ & $2.81^{\mathrm{ab}}(1.06)$ \\
Mean spleen (SD) & $2.30(0.79)$ & $1.34(1.08)$ & $1.65(0.87)$ & $1.18(1.05)$ & $0.90(1.03)$ & $1.68(1.10)$ & $1.56(1.13)$ \\
\hline
\end{tabular}

Mean log CFU/g cecum and spleen values and standard deviation (SD) are shown at 4 dpi with $10^{5}$ CFU Salmonella. Broilers were fed a diet either or not supplemented with a butyrate containing feed additive in a concentration of $3 \mathrm{~g} / \mathrm{kg}$ of sodium butyrate.

Significant differences for cecum colonization among groups are indicated with different letters ( $a, b)$. No differences for spleen colonization was detected.

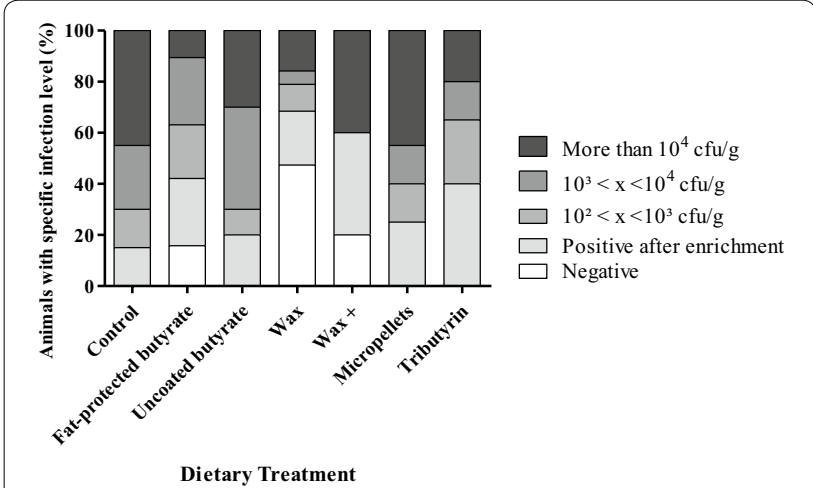

Figure 2 Colonization of Salmonella in cecum of broilers in the first trial. Colonization of Salmonella in cecum of 21-day-old broilers fed a diet either or not supplemented with a butyrate containing feed additive in a concentration of $3 \mathrm{~g} / \mathrm{kg}$ of sodium butyrate. Each dietary treatment consisted of 1 pen of 20 broilers, except for fat-protected butyrate and wax it was 1 pen of 19 each due to mortality before inoculation. The bar charts are showing the percentages of animals having a specific infection level of Salmonella as stated in the legend (specified log number of CFU per gram cecum content).

to the group fed micro encapsulated pellets $(p=0.0007)$ (Table 2). Figure 2 shows that the group fed a "wax" diet had a higher number of Salmonella negative ceca compared to the other treatment groups. No differences were detected for Salmonella colonization of the spleen when comparing the mean log CFU/g (Table 2) but, in general, a higher number of Salmonella negative spleens were found in the groups supplemented with any butyrate containing feed additive (Figure 3 ).

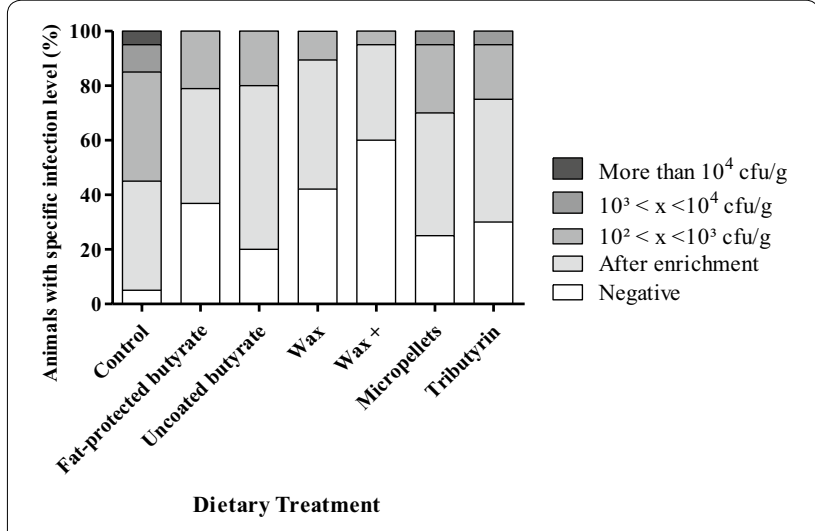

Figure 3 Colonization of Salmonella in spleen of broilers in the first trial. Colonization of Salmonella in spleen of 21-day-old broilers fed a diet either or not supplemented with a butyrate containing feed additive in a concentration of $3 \mathrm{~g} / \mathrm{kg}$ of sodium butyrate. Each dietary treatment consisted of 1 pen of 20 broilers, except for fat-protected butyrate and wax it was 1 pen of 19 each due to mortality before inoculation. The bar charts are showing the percentages of animals having a specific infection level of Salmonella as stated in the legend (specified log number of CFU per gram spleen).

\section{First trial: SCFA concentrations in ceca}

A part of the collected cecal content at 4 dpi was used to quantify the amounts of acetate, propionate and butyrate present in ceca of the sacrificed birds. The sum of acetate, propionate and butyrate concentrations in millimolar $(\mathrm{mM})$ per litre $(\mathrm{L})$ are referred to as total SCFA, and is used to calculate the relative amount of the different SCFAs present in cecum. Table 3 gives an overview 
Table 3 Concentrations of SCFAs measured in cecum of broilers in the first trial

\begin{tabular}{|c|c|c|c|c|c|c|c|}
\hline & \multicolumn{7}{|c|}{ Dietary treatment } \\
\hline & Control & $\begin{array}{l}\text { Fat-protected } \\
\text { butyrate }\end{array}$ & Uncoated butyrate & Wax & Wax+ & Micro pellets & Tributyrin \\
\hline Butyrate (mM) (SD) & $9.38^{\mathrm{a}}(3.58)$ & $13.00^{\mathrm{a}}(3.01)$ & $9.22^{\mathrm{a}}(4.69)$ & $12.93^{\mathrm{a}}(7.45)$ & $12.37^{\mathrm{a}}(3.09)$ & $11.45^{\mathrm{a}}(3.90)$ & $9.23^{\mathrm{a}}(4.67)$ \\
\hline $\begin{array}{l}\% \text { butyrate/total SCFA } \\
\text { (SD) }\end{array}$ & $14.95^{\text {ace }}(3.77)$ & $17.93^{\text {be }}(2.83)$ & $14.81^{\mathrm{a}}(5.35)$ & $25.15^{\mathrm{d}}(5.88)$ & $18.26^{\mathrm{bc}}(2.22)$ & $21.29^{\mathrm{bd}}(5.66)$ & $16.41^{\mathrm{ab}}(6.00)$ \\
\hline Acetate (mM) (SD) & $51.52^{\mathrm{ab}}(18.48)$ & $56.00^{a}(9.02)$ & $50.11^{\mathrm{ab}}(12.67)$ & $38.60^{\mathrm{ab}}(23.44)$ & $53.94^{\mathrm{ab}}(13.09)$ & $41.92^{b}(14.10)$ & $42.38^{b}(10.01)$ \\
\hline $\begin{array}{l}\text { \% acetate/total SCFA } \\
\text { (SD) }\end{array}$ & $81.43^{b}(13.29)$ & $79.11^{b c}(3.40)$ & $81.18^{b}(5.27)$ & $72.18^{\mathrm{a}}(5.45)$ & $79.26^{\mathrm{bc}}(2.66)$ & $76.43^{\mathrm{ac}}(5.22)$ & $78.55^{\mathrm{bc}}(5.46)$ \\
\hline Propionate (mM) (SD) & $2.28^{\text {bd }}(0.99)$ & $2.09^{\mathrm{ab}}(1.11)$ & $2.54^{\text {bd }}(0.97)$ & $1.31^{\mathrm{ac}}(0.95)$ & $1.65^{\mathrm{acd}}(0.76)$ & $1.23^{c}(0.68)$ & $2.54^{b}(0.97)$ \\
\hline $\begin{array}{l}\% \text { propionate/total } \\
\text { SCFA (SD) }\end{array}$ & $4.17^{\mathrm{ac}}(1.93)$ & $2.97^{b c}(1.58)$ & $4.01^{\text {ac }}(2.23)$ & $2.67^{\text {acd }}(1.36)$ & $2.47^{\mathrm{cd}}(1.13)$ & $2.28^{\text {bd }}(0.99)$ & $5.04^{\mathrm{a}}(2.54)$ \\
\hline Total SCFA (SD) & $63.18^{\mathrm{ab}}(21.01)$ & $71.09^{b}(11.15)$ & $63.34^{\mathrm{ab}}(15.12)$ & $52.84^{\mathrm{ab}}(29.62)$ & $67.96^{\mathrm{ab}}(15.45)$ & $54.6^{\mathrm{a}}(16.35)$ & $54.15^{\mathrm{a}}(12.67)$ \\
\hline
\end{tabular}

The broilers were fed a diet either or not supplemented with a butyrate containing feed additive in a concentration of $3 \mathrm{~g} / \mathrm{kg}$ of sodium butyrate radical. Each dietary treatment consisted of 1 pen of 20 broilers. Measurements of SCFA concentrations were done at the age of 21 days after 4 days of Salmonella infection.

Significant differences for SCFA concentrations or percentages among dietary treatments are indicated with different letters per row (a, b, c, $d$, e).

of those concentrations in $\mathrm{mM}$ and relative amounts of SCFA per treatment group, including differences between the treatment groups. In the text below only the differences with the control group are mentioned.

The absolute butyrate concentrations in $\mathrm{mM} / \mathrm{L}$ didn't show any differences between the treatment groups, but when comparing the relative amounts of butyrate (\% butyrate/total SCFA) present in ceca, the group fed a wax diet and micropellets had a significantly higher percentage cecal butyrate as compared to the control group (resp. $p<0.0001$ and $p=0.0043$ ).

Comparing the relative amounts of acetate concentrations (\%) showed that the wax group and the micropellet group had a significantly lower percentage of acetate compared to the control group (resp. $p<0.0001$ and $p=0.0365$ ).

The propionate concentrations $(\mathrm{mM} / \mathrm{L})$ were lower in the wax and micropellet group compared to the control group (resp. $p=0.0045, p=0.0004$ ). The relative amount of propionate present was only lower in micropellet group compared to the control group $(p=0.0034)$.

\section{Second trial: effects on Salmonella colonization}

In the second trial only the butyrate derivatives that reduced Salmonella colonization most significantly in the first trial were tested again (fat-protected butyrate and wax). All cloacal swabs taken before infection were negative for Salmonella, and no significant differences were detected in number of positive cloacal swabs after 1 $(p=0.0626)$ and $3 \mathrm{dpi}(p=0.0513)$ (Table 4$)$.

Bacteriological analysis of cecal content after $4 \mathrm{dpi}$ showed that the dietary treatment group fed with wax had a significantly reduced cecal colonization by Salmonella Enteritidis compared to the control group
Table 4 Number of cloacal swabs positive for Salmonella Enteritidis strain 147 in the second trial

\begin{tabular}{llll}
\hline & Dietary treatment & \\
\cline { 2 - 4 } & Control & $\begin{array}{l}\text { Fat-protected } \\
\text { butyrate }\end{array}$ & Wax \\
\hline $1 \mathrm{dpi}$ & $23 / 39$ & $18 / 40$ & $13 / 40$ \\
$3 \mathrm{dpi}$ & $30 / 39$ & $22 / 40$ & $21 / 40$ \\
\hline
\end{tabular}

Number of positive swabs on total per dietary treatment are given at 1 and 3 days post-infection (dpi) with $10^{5} \mathrm{CFU}$ Salmonella. Broilers were fed a diet either or not supplemented with a butyrate containing feed additive in a concentration of $3 \mathrm{~g} / \mathrm{kg}$ of sodium butyrate.

Table 5 Colonization of cecum and spleen by Salmonella Enteritidis strain 147 in the second trial

\begin{tabular}{lccr}
\hline & \multicolumn{3}{l}{ Dietary treatment } \\
\cline { 2 - 4 } & Control & Fat-protected butyrate & Wax \\
\hline Mean cecum (SD) & $3.64^{\mathrm{a}}(1.47)$ & $2.89^{\mathrm{ab}}(1.04)$ & $2.40^{\mathrm{b}}(0.76)$ \\
Mean spleen (SD) & $2.25(0.64)$ & $1.93(0.08)$ & $1.94(0.12)$
\end{tabular}

Mean log CFU/g cecum and spleen values and standard deviation (SD) are shown at $4 \mathrm{dpi}$ with $10^{5} \mathrm{CFU}$ Salmonella. Broilers were fed a diet either or not supplemented with a butyrate containing feed additive in a concentration of 3 $\mathrm{g} / \mathrm{kg}$ of sodium butyrate.

Significant differences for cecum colonization among groups are indicated with different letters $(a, b)$. No differences for spleen colonization was detected.

$(p<0.0001)$ (Table 5). Figure 4 shows that the broilers fed a "wax" diet had a lower number of Salmonella positive ceca after direct plating compared to the other treatment groups. Bacterial counts in spleen revealed no differences in Salmonella colonization comparing the mean log $\mathrm{CFU} / \mathrm{g}$ (Table 5), but in general a lower number of caeca were found to have Salmonella positive samples after 


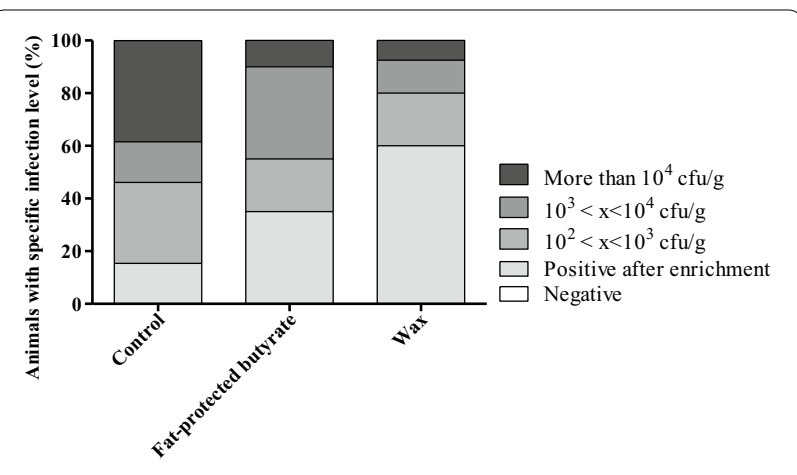

Dietary Treatment

Figure 4 Colonization of Salmonella in ceca of broilers in the second trial. Colonization of Salmonella in ceca of 21-day-old broilers fed a diet either or not supplemented with a butyrate containing feed additive in a concentration of $3 \mathrm{~g} / \mathrm{kg}$ of sodium butyrate. Each dietary treatment consisted of 2 pens of 20 broilers. The bar charts are showing the percentages of animals having a specific infection level of Salmonella as stated in the legend (specified log number of CFU per gram cecum content).

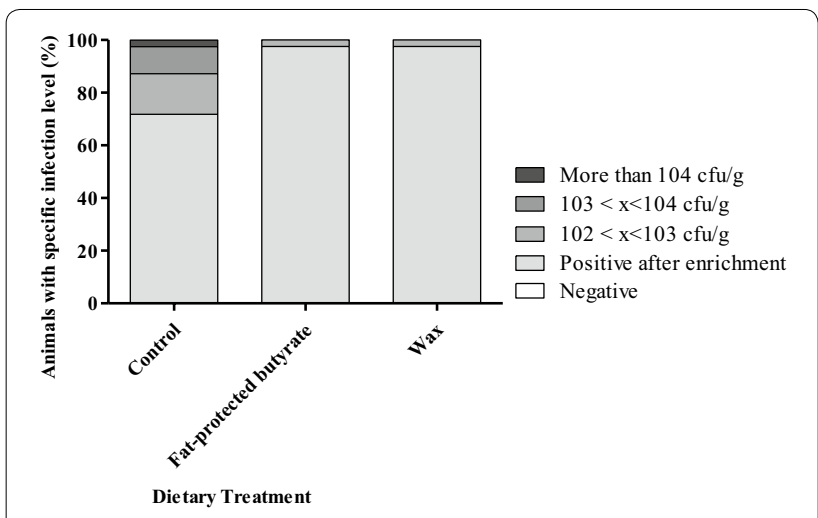

Figure 5 Colonization of Salmonella in spleen of broilers in the second trial. Colonization of Salmonella in spleen of 21-day-old broilers fed a diet either or not supplemented with a butyrate containing feed additive in a concentration of $3 \mathrm{~g} / \mathrm{kg}$ of sodium butyrate. Each dietary treatment consisted of 2 pens of 20 broilers. The bar charts are showing the percentages of animals having a specific infection level of Salmonella as stated in the legend (specified log number of CFU per gram spleen content).

direct plating in the groups supplemented with a butyrate containing feed additive (Figure 5).

\section{Second trial: SCFA concentrations in cecum}

Fat-protected butyrate yielded the highest total SCFA concentration of all tested groups, which was significantly higher compared to the wax treatment $(p=0.0008)$. Table 6 gives an overview of those concentrations in
$\mathrm{mM}$ and relative amounts of SCFA per treatment group, including differences between the treatment groups.

Both absolute $(\mathrm{mM})$ as well as relative (\%) butyrate concentrations were significantly higher for both treatment groups compared to the control group [control vs fat-protected butyrate (mM $p=0.0017, \% p=0.0096)$, control vs wax $(\mathrm{mM}$ and $\% p<0.0001)])$. The relative amount of butyrate was higher for the wax group compared to the fat-protected butyrate group $(p<0.0001)$.

The wax treatment group had a higher butyrate concentration, but a significantly lower acetate and propionate concentration compared to the control group, both in absolute and relative numbers (mM acetate $p=0.0013$, \% acetate $p<0.0001$, $\mathrm{mM}$ propionate $p=0.0116$; \% propionate $p=0.0008)$. Fat-protected butyrate yielded a higher concentration of acetate relative to the total SCFA and in $\mathrm{mM}$ compared to wax $(p<0.0001)$, and relatively higher percentage of acetate compared to the control group $(p=0.0037)$. Only in absolute numbers the propionate concentration was higher in the fat-protected butyrate group compared to the control group $(p=0.0058)$.

\section{S rDNA V3-V4 sequencing}

Cecal content was collected from the 21-day-old chickens in the first trial, 4 days after Salmonella infection, in groups receiving a standard diet supplemented with wax or fat-protected butyrate, or non-supplemented diet for 21 consecutive days. DNA was extracted from the cecal content, and samples were sent for Illumina sequencing. Diversity or beta diversity of the cecal bacterial communities of chickens in the control group and the group receiving wax and fat-protected butyrate are shown in a PCoA plot based on the Bray-Curtis dissimilarity index (Figure 6). The PCoA plot of the abundance based on Bray-Curtis dissimilarity matrix showed diet-related clustering $(p<0.001)$. Analyzing the alpha diversity, or richness, of the cecal content, expressed as the number of observed OTUs, revealed no significant differences between the dietary treatment groups (Figure 7).

Members of the phylum Proteobacteria were significantly decreased in cecal contents from chickens that received the diet containing wax $(0.6 \% p=0.0004)$ or fat-protected butyrate $(0.9 \% p=0.0037)$ compared to the non-supplemented group (3.2\%) (Figure 8). The same reduction was observed at family and genus level for resp. Enterobacteriaceae and Escherichia/Shigella (Table 7).

Figure 9 shows the relative abundances observed at family level. The most abundant family in analyzed samples was Lachnospiraceae, which was significantly increased in the wax group (62.5\%) compared to the control group $(52.8 \% p=0.0181)$. A large proportion of this family was assigned to uncultured genera. Those OTUs together with the ones assigned to genus Blautia were 
Table 6 Concentrations of SCFAs measured in cecum of broilers in the second trial

\begin{tabular}{lcrr}
\hline & \multicolumn{2}{c}{ Dietary treatment } & \\
\cline { 2 - 4 } & Control & Fat-protected butyrate & Wax \\
\hline Butyrate (mM) (SD) & $8.48^{\mathrm{a}}(2.69)$ & $12.45^{\mathrm{b}}(3.94)$ & $13.45^{\mathrm{b}}(3.32)$ \\
\% butyrate/total SCFA (SD) & $15.02^{\mathrm{a}}(2.75)$ & $18.39^{\mathrm{b}}(2.89)$ & $27.16^{\mathrm{c}}(4.37)$ \\
Acetate (mM) (SD) & $47.55^{\mathrm{a}}(14.12)$ & $52.2^{\mathrm{a}}(9.74)$ & $34.4^{\mathrm{b}}(7.65)$ \\
\% acetate/total SCFA (SD) & $82.70^{\mathrm{a}}(3.46)$ & $78.71^{\mathrm{b}}(2.80)$ & $69.09^{\mathrm{c}}(4.45)$ \\
Propionate (mM) (SD) & $1.25^{\mathrm{a}}(0.51)$ & $1.87^{\mathrm{b}}(0.69)$ & $1.83^{\mathrm{b}}(0.56)$ \\
\% propionate/total SCFA (SD) & $2.29^{\mathrm{a}}(1.00)$ & $2.89^{\mathrm{ab}}(1.20)$ & $3.75^{\mathrm{b}}(1.28)$ \\
Total SCFA (SD) & $57.29^{\mathrm{ab}}(16.4)$ & $67.27^{\mathrm{a}}(13.23)$ & $49.67^{\mathrm{b}}(9.80)$ \\
\hline
\end{tabular}

The broilers were fed a diet either or not supplemented with a butyrate containing feed additive in a concentration of $3 \mathrm{~g} / \mathrm{kg}$ of sodium butyrate radical. Each dietary treatment consisted of 2 pens of 20 broilers. Measurements of SCFA concentrations were done at the age of 21 days after 4 days of Salmonella infection.

Significant differences for SCFA concentrations or percentages among dietary treatments are indicated with different letters per row (a, b).

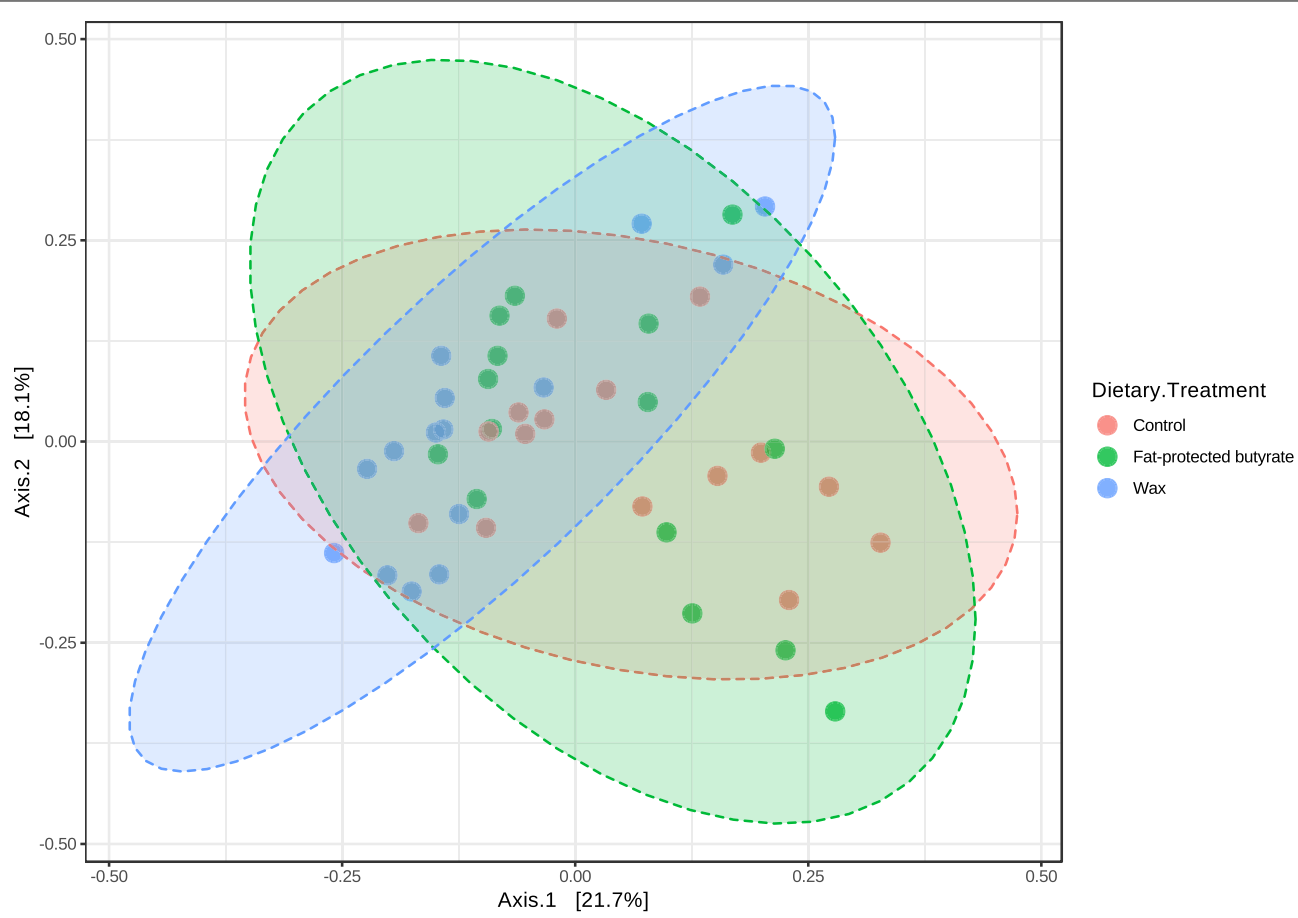

Figure 6 Diversity measures (beta-diversity) for the cecal bacterial communities in the second trial. Diversity measures (beta-diversity) for the cecal bacterial communities of chickens in the control group, and the groups receiving wax and fat-protected butyrate. Cecal content was collected from the 21-day-old chickens in the first trial, 4 days after Salmonella infection, while receiving a standard diet supplemented with wax (blue) or fat-protected butyrate (green) or non-supplemented (pink) for 21 consecutive days. The PCoA plot of the abundance based on BrayCurtis dissimilarity matrix showed diet-related clustering indicated with ellipses with $p$-value $<0.001$, and was created with the web-based tool MicrobiomeAnalyst [47].

responsible for the shift to Lachnospiraceae in the wax group (Table 7).

Although no reduction of the abundance of the family Ruminococcaceae could be observed for the wax group compared to the control group $(p=0.0815)$, the genus Subdoligranulum within this family was significantly decreased in the wax group $(0.3 \%)$ compared to the control group $(4.6 \%, p=0.0169)$ (Table 7).
The relative abundance of Lactobacillaceae was significantly decreased for the wax group (3.8\%) versus the control group $(10.2 \% p=0.0028)$, which was solely due to the reduction of the genus Lactobacillus.

Members of the family VadinBB60 were increased in abundance for the group receiving a diet containing wax (3.6\%) compared to the control group $(1.1 \% p=0.0021)$. 


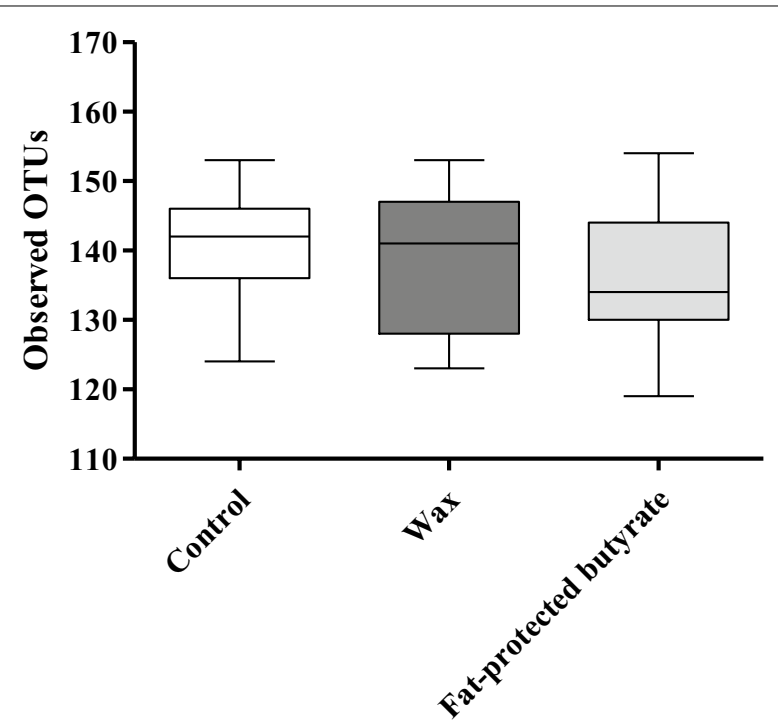

Figure 7 Richness measures (alpha diversity) for the cecal bacterial communities in the second trial. The richness has been visualized for the control group and the group receiving wax and fat-protected butyrate. Cecal content was collected from the 21-day-old chickens in the first trial 4 days after Salmonella infection and receiving a standard diet supplemented with wax or fat-protected butyrate or non-supplemented diet for 21 consecutive days. The horizontal lines at the bottom, the middle and the top of the box represent the first quartile, median and third quartile, respectively. The whiskers indicate the $\mathrm{min} / \mathrm{max}$ value.

Other significant differences were observed at family level with lower abundances for the families Defluviitaleaceae and Peptoniphilaceae (Table 7).

\section{Discussion}

One of the challenges in the use of butyrate as feed additive is having a reliable system to deliver the molecule to the preferred location in the intestinal tract. Mainly two techniques can be found in the literature, being esters composed of butyric acid and glycerol, and butyrate embedded in a matrix of vegetable fat developed by spray cooling or film coating. The first is believed to yield higher butyrate concentrations in the upper GI tract while the latter would carry butyrate further down the GI tract, although data on effective butyrate concentrations in the gut of poultry are scarce in the literature [30]. In the pharmaceutical field one of the strategies to bring active compounds past the gastric section in the GIT and induce a sustained release, is production of matrix pellets by melt granulation based on microcrystalline waxes and starch derivatives. Drug release can be influenced by the processing parameters as well as the amount of starch due to change of matrix solubility [15]. Another strategy to bypass the stomach for orally administered pharmaceuticals, is the production of coated pellets by extrusion and spheronization and applying an enteric coating. The type of coating determines the drug release, and plays an important role in protecting drugs that are decomposable in the stomach by low $\mathrm{pH}$ or enzymatic degradation. A very site-specific release of the drug can be obtained with different types of coatings based on $\mathrm{pH}$ in the GIT, such as coated pellets for colon delivery with a coating soluble at $\mathrm{pH} 7$ or higher [31].

Previous in vitro research showed that the matrix pellets based on microcrystalline wax had a sustained release profile with an increased release of butyrate at the simulated ileum. Commercially available fat-coated butyrate products with a different production process than the wax matrices (spray chilling vs hot melt extrusion) showed variations in release properties. Only two of the commercially tested products had an extended release profile in vitro. In previous work, micropellets showed a targeted release profile. They were partially protected during gastric passage, followed by a rapid release in the enteric segments reaching $\mathrm{pH} 6.5$ which was expected with the type of coating used [13]. We investigated the potential of newly developed butyrate derivatives and one commercially available fat-coated butyrate product with extended release profile to increase butyrate concentration in the ceca and to reduce colonization of Salmonella in the ceca. It was hypothesized that a more sustained release and an increase in cecal butyrate concentrations would decrease Salmonella colonization in the ceca. The butyrate effect on Salmonella is through suppression of invasion of Salmonella in epithelial cells and consequently gut colonization [32]. One of the important transcriptional activators of Salmonella pathogenicity island 1 (SPI1) that regulates the invasion of Salmonella is the hilA gene [33]. Mutants in this gene have been shown to be poor gut colonizers [34]. Previously downregulation of hilA gene after exposure to butyrate and propionate was reported, while expression increased after exposure of the bacteria to acetate [32,35]. In our study we showed that in the ceca of chickens fed a wax matrix the relative proportion of butyrate increased, while acetate proportion was reduced compared to the control group. This shift in SCFA proportions indicates a less favorable environment for Salmonella to invade the epithelial cells of the cecal mucosa increasing the resilience of chickens against Salmonella infections. The results of increased SCFA concentrations in the hindgut are in line with the findings of Van den Borne [14], but in contrast with the research of Moquet et al. where no statistical differences could be observed in cecum and colon concentrations, but only numerical differences after feeding with the same fat-protected butyrate (although a large variation within the groups was reported) [13]. Although the birds were roughly the same age, the type of challenge may 


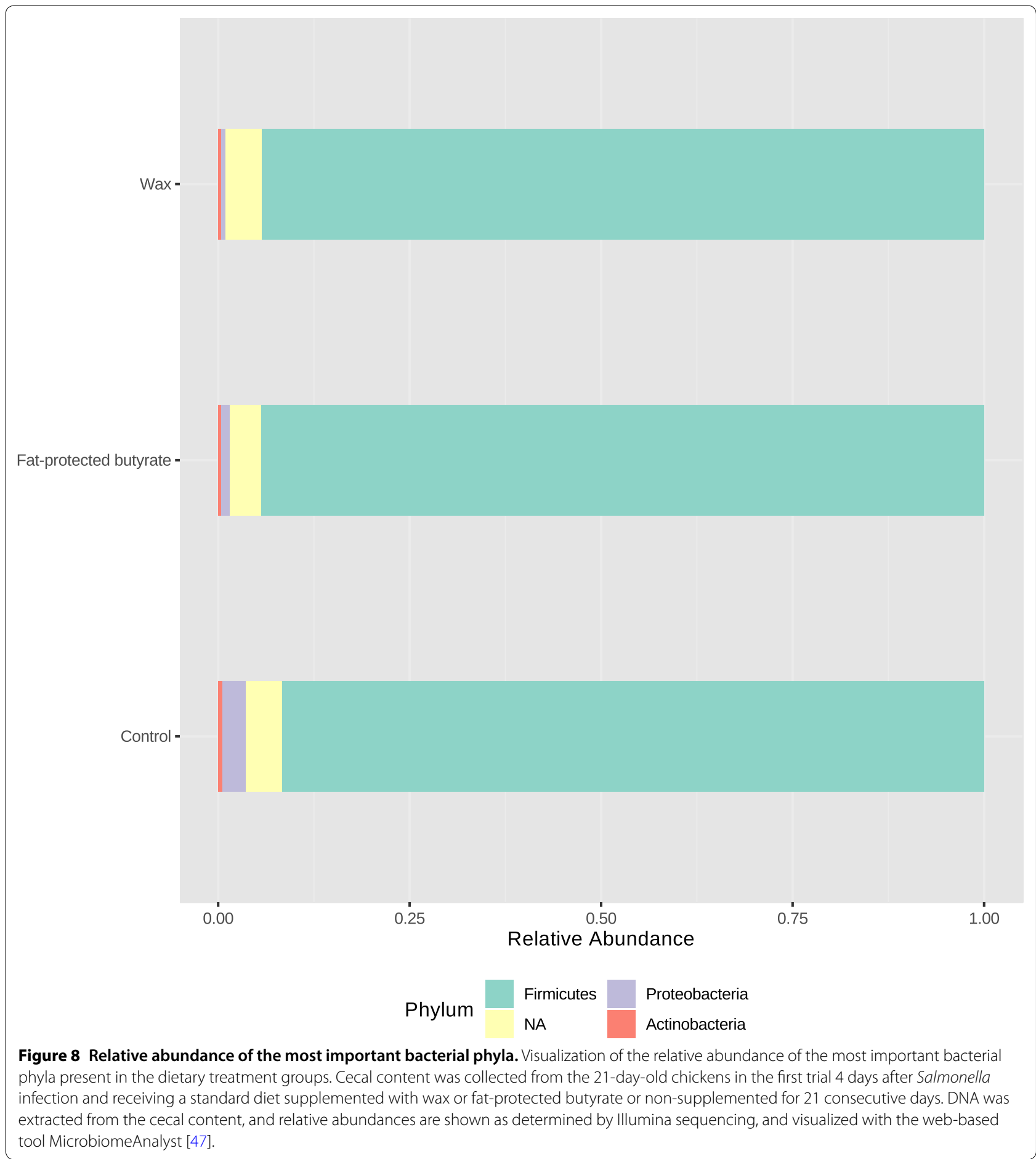

play a role in these discrepancies, namely bacterial challenge by Salmonella infection versus a dietary challenge induced by rapeseed meal diet.

Literature indicates that supplementing diets of broilers with butyrate influences cecal microbiota composition in a way that is beneficial for the health and growth performance when the microbiota is disturbed by for example an enteric disease or nutritional challenge [3638]. We also observed that supplementing butyrate in a wax-based carrier can reduce the Salmonella count, which very likely explains the observed decrease of Enterobacteriaceae. We observed that wax coated butyrate 
Table 7 Relative abundances of bacterial phyla, families and genera in the microbial community in ceca of broilers

\begin{tabular}{|c|c|c|c|c|c|c|c|c|}
\hline \multirow[t]{3}{*}{ Phylum } & \multirow[t]{3}{*}{ Family } & \multirow[t]{3}{*}{ Genus } & \multicolumn{6}{|c|}{ Dietary treatment } \\
\hline & & & \multicolumn{2}{|l|}{ Control } & \multicolumn{2}{|l|}{ Wax } & \multicolumn{2}{|c|}{$\begin{array}{l}\text { Fat-protected } \\
\text { butyrate }\end{array}$} \\
\hline & & & Mean & SD & Mean & SD & Mean & SD \\
\hline \multirow[t]{15}{*}{ Firmicutes } & & & $91.63^{\mathrm{a}}$ & 6.10 & $93.94^{\mathrm{a}}$ & 2.92 & $94.57^{\mathrm{a}}$ & 2.73 \\
\hline & \multirow[t]{3}{*}{ Lachnospiraceae } & & $52.75^{\mathrm{a}}$ & 12.17 & $62.48^{b}$ & 6.13 & $50.68^{\mathrm{a}}$ & 11.56 \\
\hline & & Blautia & $12.12^{\mathrm{a}}$ & 4.26 & $16.44^{b}$ & 4.87 & $12.96^{\mathrm{ab}}$ & 4.51 \\
\hline & & Other/uncultured & $29.80^{a}$ & 10.22 & $37.83^{b}$ & 7.05 & $29.72^{\mathrm{ab}}$ & 11.06 \\
\hline & \multicolumn{2}{|l|}{ Ruminococcaceae } & $18.38^{\mathrm{ab}}$ & 9.15 & $13.85^{\mathrm{a}}$ & 4.85 & $24.15^{\mathrm{b}}$ & 9.19 \\
\hline & & Subdoligranulum & $4.56^{\mathrm{a}}$ & 7.44 & $0.31^{b}$ & 0.41 & $5.85^{\mathrm{ab}}$ & 10.65 \\
\hline & & Anaerotruncus & $2.55^{\mathrm{a}}$ & 1.66 & $2.23^{\mathrm{a}}$ & 1.51 & $2.98^{\mathrm{a}}$ & 1.65 \\
\hline & & Other/uncultured & $11.03^{\mathrm{a}}$ & 4.18 & $11.19^{a}$ & 4.04 & $14.69^{\mathrm{a}}$ & 5.16 \\
\hline & \multicolumn{2}{|l|}{ Lactobacillaceae } & $10.22^{\mathrm{a}}$ & 8.19 & $3.82^{b}$ & 3.86 & $7.54^{\mathrm{ab}}$ & 6.14 \\
\hline & & Lactobacillus & $10.22^{\mathrm{a}}$ & 8.19 & $3.82^{b}$ & 3.86 & $7.54^{\mathrm{ab}}$ & 6.14 \\
\hline & \multicolumn{2}{|l|}{ Streptococcaceae } & $7.91^{\mathrm{a}}$ & 4.54 & $8.34^{\mathrm{a}}$ & 4.95 & $7.96^{\mathrm{a}}$ & 3.00 \\
\hline & \multicolumn{2}{|l|}{ VadinBB60 } & $1.14^{\mathrm{a}}$ & 1.02 & $3.62^{b}$ & 2.33 & $2.44^{\mathrm{ab}}$ & 2.77 \\
\hline & \multicolumn{2}{|l|}{ Defluviitaleaceae } & $0.15^{\mathrm{a}}$ & 0.05 & $0.30^{b}$ & 0.16 & $0.03^{b}$ & 0.14 \\
\hline & \multicolumn{2}{|l|}{ Peptoniphilaceae } & $0.05^{\mathrm{a}}$ & 0.04 & $0.01^{b}$ & 0.02 & $0.00^{\mathrm{b}}$ & 0.01 \\
\hline & \multicolumn{2}{|c|}{ Lachnospiraceae + Ruminococcaceae } & $71.13^{\mathrm{a}}$ & 8.11 & $76.33^{\mathrm{a}}$ & 6.84 & $74.84^{\mathrm{a}}$ & 7.19 \\
\hline \multirow[t]{3}{*}{ Proteobacteria } & & & $3.16^{\mathrm{a}}$ & 5.28 & $0.56^{\mathrm{b}}$ & 0.45 & $0.91^{\mathrm{b}}$ & 1.32 \\
\hline & \multicolumn{2}{|l|}{ Enterobacteriaceae } & $1.80^{\mathrm{a}}$ & 1.21 & $0.54^{\mathrm{b}}$ & 0.44 & $0.29^{b}$ & 1.32 \\
\hline & & Escherichia/Shigella & $1.76^{\mathrm{a}}$ & 1.17 & $0.54^{b}$ & 0.44 & $0.88^{b}$ & 1.33 \\
\hline \multicolumn{3}{|l|}{ Actinobacteria } & $91.64^{\mathrm{a}}$ & 6.10 & $93.94^{\mathrm{a}}$ & 2.92 & $94.58^{\mathrm{a}}$ & 2.73 \\
\hline \multicolumn{3}{|l|}{ Other } & $4.69^{\mathrm{a}}$ & 3.58 & $5.03^{\mathrm{a}}$ & 2.87 & $4.11^{\mathrm{a}}$ & 2.20 \\
\hline
\end{tabular}

At the age of 21 days after 4 days of Salmonella infection relative abundances in cecal content were determined with $16 \mathrm{~S}$ rRNA V3-V4 amplicon sequencing. The broilers were fed a diet either or not supplemented with a butyrate containing feed additive in a concentration of $3 \mathrm{~g} / \mathrm{kg}$ of sodium butyrate. Each dietary treatment consisted of 2 pens of 20 broilers.

Significant differences for relative abundances of bacterial phyla, families and genera among dietary treatments are indicated with different letters per row ( $\mathrm{a}$, b).

increased the relative abundance of Lachnospiraceae, a family containing important butyrate-producing bacteria. Besides an increase of genera within this family that are not yet cultured, members of the genus Blautia were also increased with wax supplementation. Species belonging to Blautia can use carbohydrates as a substrate to produce lactate and acetate as the major end product of glucose fermentation $[39,40]$. They are associated with a reduction of incidence of inflammatory bowel disease in humans [41]. Another family with important butyrateproducers is Ruminococcaceae. Subdoligranulum, one of the genera in this family that has butyric and lactic acid as major end products of fermentation, was decreased in abundance after wax supplementation in this study [42]. Analyzing the sum of both families resulted in no differences between the dietary treatment groups. Accordingly, it is not clear whether the observed increased concentrations in cecal butyrate in the supplemented groups are mainly due to the exogenous butyrate or whether endogenous butyrate is also adding on top of this.
In our study a significant decrease of cecal Lactobacillaceae was observed when butyrate was added to the diet in a wax or fat-coated form. Lactobacillus spp. are probably the most commonly used probiotics and they are linked to several benefits for intestinal health [43]. Several other studies with butyrate supplementation reported the same observation regarding Lactobacillus reductions, both in broilers in cecal lumen as well as in weaned piglets in ileal and colonic lumen $[44,45]$. Based on a previous study by De Boever et al. showing that Lactobacillus reuteri plays an active role in microbial bile salt hydrolase production resulting in impaired lipid absorption and therefore dietary energy losses, it is hypothesized that a reduction of Lactobacillaceae can play a role in reduced energy loss, and thus increases nutrient utilization with a better feed conversion ratio as profitable result [46]. In a recent study in pigs, a better feed efficiency was correlated amongst others with an increase of Clostridiales genus VadinBB60 [46]. In our study a higher abundance of VadinBB60 was observed with wax dietary treatment, but feed conversion ratio was not evaluated. 


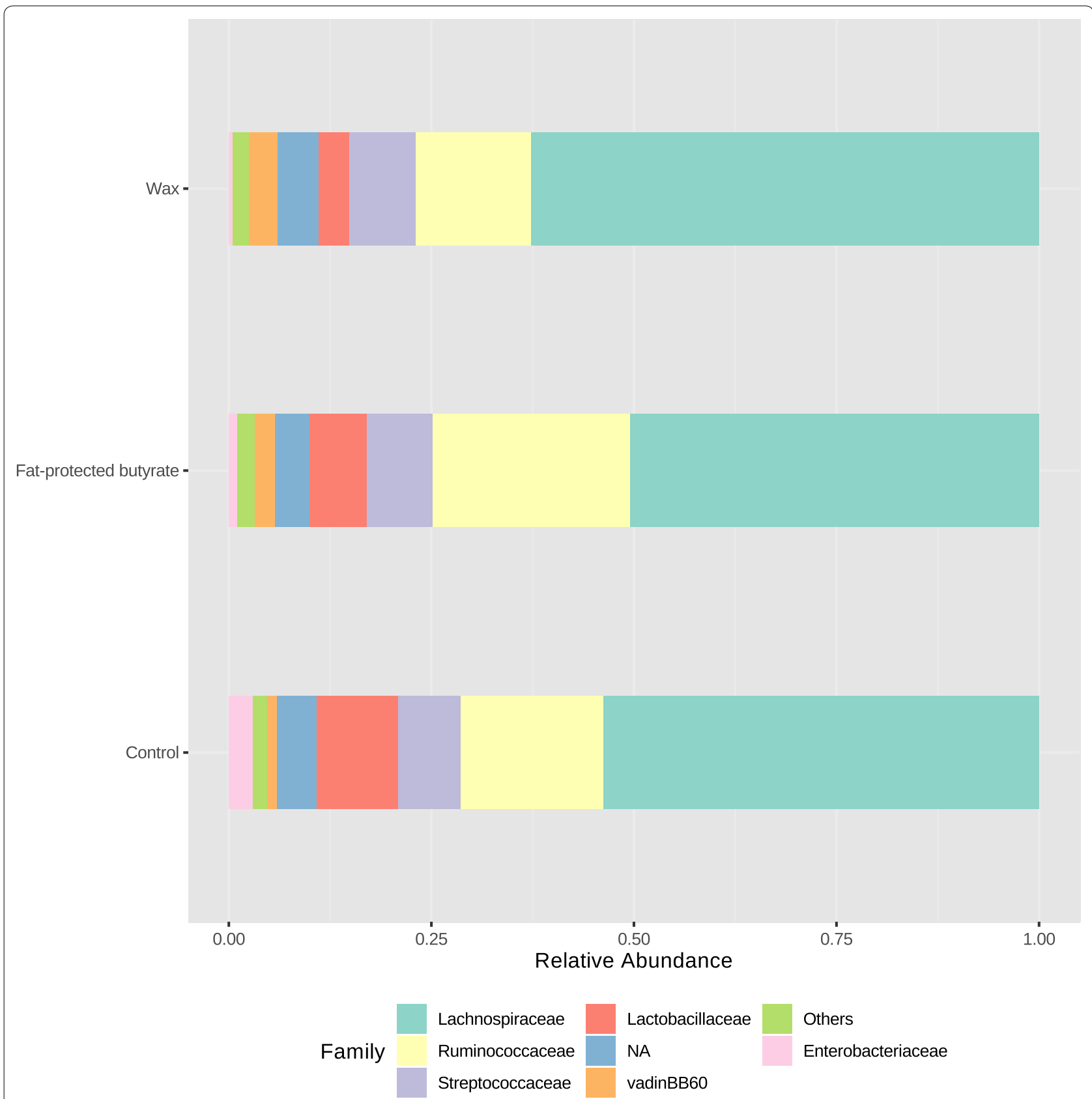

Figure 9 Relative abundance of the most abundant bacterial families. Visualization of the relative abundance of the most abundant bacterial families present in the caeca of animals in the different dietary treatment groups. Cecal content was collected from the 21-day-old chickens in the first trial 4 days after Salmonella infection and receiving a standard diet supplemented with wax or fat-protected butyrate or non-supplemented for 21 consecutive days. DNA was extracted from the cecal content, and relative abundances are shown as determined by Illumina sequencing, and visualized with the web-based tool MicrobiomeAnalyst [47].

In conclusion, the newly developed microcrystalline wax matrix as carrier for sodium butyrate may be a suitable feed supplement to protect broilers against Salmonella Enteritidis. In this study the matrix was tested against a single strain Salmonella Enteritidis 147 Strep, which is known to colonize the gut and internal organs of chickens to a high level. Compared to other carriers, the delayed release of butyrate induced a higher relative cecal butyrate concentration and a decrease of Salmonella colonization in ceca. The dietary treatment of wax containing sodium butyrate modulated the cecal microbiota of the challenged chickens. 


\begin{abstract}
Abbreviations
CFU: colony-forming unit; PBS: Phosphate-buffered saline; SCFA: short chain fatty acids; GIT: gastro intestinal tract; mc: microcrystalline; mM: millimolair; XLD: xylose lysine deoxycholate; HBSS: Hank's Balanced Salt Solution; DNA: Deoxyribonucleic acid; rDNA: Ribosomal deoxyribonucleic acid; CTAB: cetyl trimethylammonium bromide; PEG: polyethyleenglycol; OTU: Operational taxonomic unit; ANOVA: Analysis of variance; PERMANOVA: Permutational multivariate analysis of variance; PCoA: principal coordinate analysis.
\end{abstract}

\section{Acknowledgements}

The authors would like to thank Dr Pierre Moquet and Dr Andre Antunes for the technical support and assistance during the production and development of the pharmaceutical prototypes.

\section{Authors' contributions}

$L O, R D$ and Fvl contributed to the study design. LO conceived the study, performed animal trial and laboratory assays. LO produced the first version of the manuscript with results interpretation and discussion inputs from RD, Fvl and FH. SB analyzed the sequencing data and edited the manuscript. All authors read and approved the final manuscript.

\section{Funding}

This study was supported by a grant of the IWT (Agentschap voor Innovatie door Wetenschap en Technologie, grant no. 120860).

\section{Availability of data}

All data generated during this study are included in this published article. The datasets used and/or analyzed during the current study are available from the corresponding author on reasonable request.

\section{Ethics approval and consent to participate}

The experiments involving animals were approved by the ethical committee of the Faculty of Veterinary Medicine, Ghent University (EC 2014/135 and EC2015/46). All animals were handled in strict accordance with good clinical practices and all efforts were made to minimize suffering.

\section{Competing interests}

The authors declare that they have no competing interests.

\section{Author details}

1 Department of Pathology, Bacteriology and Avian Diseases, Faculty of Veterinary Medicine, Ghent University, Salisburylaan 133, 9820 Merelbeke, Belgium. 2 Plant Sciences Unit, Flanders Research Institute for Agriculture, Fisheries and Food (ILVO), Merelbeke, Belgium.

Received: 17 January 2020 Accepted: 20 March 2020

Published online: 19 April 2020

\section{References}

1. Koutsoumanis K, Allende A, Alvarez-Ordonez A, Bolton D, Bover-Cid S, Chemaly M, De Cesare A, Herman L, Hilbert F, Lindqvist R, Nauta M, Peixe L, Ru G, Simmons M, Skandamis P, Suffredini E, Dewulf J, Hald T, Michel V, Niskanen T, Ricci A, Snary E, Boelaert F, Messens W, Davies R, Hazards EPB (2019) Salmonella control in poultry flocks and its public health impact. EFSA J 17:5596

2. Antunes P, Mourao J, Campos J, Peixe L (2016) Salmonellosis: the role of poultry meat. Clin Microbiol Infect 22:110-121

3. De Cesare A (2018) Salmonella in foods: a reemerging problem. Adv Food Nutr Res 86:137-179

4. Gantois I, Ducatelle R, Pasmans F, Haesebrouck F, Gast R, Humphrey TJ, Van Immerseel F (2009) Mechanisms of egg contamination by Salmonella Enteritidis. FEMS Microbiol Rev 33:718-738

5. Liu JD, Bayir HO, Cosby DE, Cox NA, Williams SM, Fowler J (2017) Evaluation of encapsulated sodium butyrate on growth performance, energy digestibility, gut development, and Salmonella colonization in broilers. Poult Sci 96:3638-3644
6. Cerisuelo A, Marin C, Sanchez-Vizcaino F, Gomez EA, de la Fuente JM, Duran R, Fernandez C (2014) The impact of a specific blend of essential oil components and sodium butyrate in feed on growth performance and Salmonella counts in experimentally challenged broilers. Poult Sci 93:599-606

7. Van Immerseel F, Boyen F, Gantois I, Timbermont L, Bohez L, Pasmans F, Haesebrouck F, Ducatelle R (2005) Supplementation of coated butyric acid in the feed reduces colonization and shedding of Salmonella in poultry. Poult Sci 84:1851-1856

8. Zhang WH, Jiang Y, Zhu QF, Gao F, Dai SF, Chen J, Zhou GH (2011) Sodium butyrate maintains growth performance by regulating the immune response in broiler chickens. Br Poult Sci 52:292-301

9. Guilloteau P, Martin L, Eeckhaut V, Ducatelle R, Zabielski R, Van Immerseel F (2010) From the gut to the peripheral tissues: the multiple effects of butyrate. Nutr Res Rev 23:366-384

10. Fernandez-Rubio C, Ordonez C, Abad-Gonzalez J, Garcia-Gallego A, Honrubia MP, Mallo JJ, Balana-Fouce R (2009) Butyric acid-based feed additives help protect broiler chickens from Salmonella Enteritidis infection. Poult Sci 88:943-948

11. Boyen F, Haesebrouck F, Vanparys A, Volf J, Mahu M, Van Immerseel F, Rychlik I, Dewulf J, Ducatelle R, Pasmans F (2008) Coated fatty acids alter virulence properties of Salmonella Typhimurium and decrease intestinal colonization of pigs. Vet Microbiol 132:319-327

12. Bedford A, Gong J (2018) Implications of butyrate and its derivatives for gut health and animal production. Anim Nutr 4:151-159

13. Moquet PCA (2018) Butyrate in broiler diets. Impact of butyrate presence in distinct gastrointestinal tract segments on digestive function, microbiota composition and immune responses. Ph.D., Wageningen University

14. van den Borne JJGC, Heetkamp MJW, Buyse J, Niewold TA (2015) Fat coating of $\mathrm{Ca}$ butyrate results in extended butyrate release in the gastrointestinal tract of broilers. Livest Sci 175:96-100

15. Zhou F, Vervaet C, Remon JP (1997) Influence of processing on the characteristics of matrix pellets based on microcrystalline waxes and starch derivatives. Int J Pharm 147:23-30

16. Louis P, Duncan SH, McCrae SI, Millar J, Jackson MS, Flint HJ (2004) Restricted distribution of the butyrate kinase pathway among butyrateproducing bacteria from the human colon. J Bacteriol 186:2099-2106

17. Ravindran V (2013) Feed enzymes: the science, practice, and metabolic realities. J Appl Poult Res 22:628-636

18. Doreau M, Chilliard Y (1997) Digestion and metabolism of dietary fat in farm animals. Br J Nutr 78:S15-S35

19. Moreau H, Gargouri Y, Lecat D, Junien JL, Verger R (1988) Screening of preduodenal lipases in several mammals. Biochim Biophys Acta 959:247-252

20. Methner U, Alshabibi S, Meyer H (1995) Experimental oral infection of specific pathogen-free laying hens and cocks with Salmonella-Enteritidis strains. Zentralbl Veterinarmed B 42:459-469

21. De Cort W, Geeraerts S, Balan V, Elroy M, Haesebrouck F, Ducatelle R, Van Immerseel F (2013) A Salmonella Enteritidis hilAssrAfliG deletion mutant is a safe live vaccine strain that confers protection against colonization by Salmonella Enteritidis in broilers. Vaccine 31:5104-5110

22. De Weirdt R, Possemiers S, Vermeulen G, Moerdijk-Poortvliet TC, Boschker HT, Verstraete W, Van de Wiele T (2010) Human faecal microbiota display variable patterns of glycerol metabolism. FEMS Microbiol Ecol 74:601-611

23. Griffiths RI, Whiteley AS, O'Donnell AG, Bailey MJ (2000) Rapid method for coextraction of DNA and RNA from natural environments for analysis of ribosomal DNA- and rRNA-based microbial community composition. Appl Environ Microbiol 66:5488-5491

24. Kowalchuk GA, Naoumenko ZS, Derikx PJ, Felske A, Stephen JR, Arkhipchenko IA (1999) Molecular analysis of ammonia-oxidizing bacteria of the beta subdivision of the class Proteobacteria in compost and composted materials. Appl Environ Microbiol 65:396-403

25. Vermeulen K, Verspreet J, Courtin CM, Haesebrouck F, Baeyen S, Haegeman A, Ducatelle R, Van Immerseel F (2018) Reduced-particle-size wheat bran is efficiently colonized by a lactic acid-producing community and reduces levels of Enterobacteriaceae in the cecal microbiota of broilers. Appl Environ Microbiol 84:e01343-e01418

26. Caporaso JG, Kuczynski J, Stombaugh J, Bittinger K, Bushman FD, Costello EK, Fierer N, Pena AG, Goodrich JK, Gordon Jl, Huttley GA, Kelley ST, Knights D, Koenig JE, Ley RE, Lozupone CA, McDonald D, Muegge BD, 
Pirrung M, Reeder J, Sevinsky JR, Turnbaugh PJ, Walters WA, Widmann J, Yatsunenko T, Zaneveld J, Knight R (2010) QIIME allows analysis of highthroughput community sequencing data. Nat Methods 7:335-336

27. Clark RA, Shoaib M, Hewitt KN, Stanford SC, Bate ST (2012) A comparison of InVivoStat with other statistical software packages for analysis of data generated from animal experiments. J Psychopharmacol 26:1136-1142

28. Munzel U, Hothorn LA (2001) A unified approach to simultaneous rank test procedures in the unbalanced one-way layout. Biometrical J 43:553-569

29. Dixon P (2003) VEGAN, a package of R functions for community ecology. J Veg Sci 14:927-930

30. Moquet PCA, Onrust L, van Immerseel F, Ducatelle R, Hendriks WH, Kwakkel RP (2016) Importance of release location on the mode of action of butyrate derivatives in the avian gastrointestinal tract. World Poultry Sci J 72:61-80

31. Rhee Y, Lee J, Lee B, Park E (2010) Controlled-release pelletized dosage forms using the extrusion-spheronization process. J Pharm Invest 40:103-112

32. Van Immerseel F, De Buck J, Pasmans F, Velge P, Bottreau E, Fievez V, Haesebrouck F, Ducatelle R (2003) Invasion of Salmonella enteritidis in avian intestinal epithelial cells in vitro is influenced by short-chain fatty acids. Int J Food Microbiol 85:237-248

33. Fahlen TF, Mathur N, Jones BD (2000) Identification and characterization of mutants with increased expression of hilA, the invasion gene transcriptional activator of Salmonella typhimurium. FEMS Immunol Med Microbiol 28:25-35

34. Bohez L, Ducatelle R, Pasmans F, Botteldoorn N, Haesebrouck F, Van Immerseel F (2006) Salmonella enterica serovar Enteritidis colonization of the chicken caecum requires the HilA regulatory protein. Vet Microbiol 116:202-210

35. Durant JA, Corrier DE, Ricke SC (2000) Short-chain volatile fatty acids modulate the expression of the hilA and invF genes of Salmonella Typhimurium. J Food Protect 63:573-578

36. Bortoluzzi C, Pedroso AA, Mallo JJ, Puyalto M, Kim WK, Applegate TJ (2017) Sodium butyrate improved performance while modulating the cecal microbiota and regulating the expression of intestinal immunerelated genes of broiler chickens. Poult Sci 96:3981-3993

37. Bortoluzzi C, Rothrock MJ, Serpa Vieira BS, Mallo JJ, Puyalto M, Hofacre C, Applegate TJ (2018) Supplementation of protected sodium butyrate alone or in combination with essential oils modulated the cecal microbiota of broiler chickens challenged with coccidia and Clostridium perfringens. Front Sustain Food Syst 2:72
38. Zhou ZY, Nie K, Huang QZ, Li K, Sun YY, Zhou RQ, Wang ZY, Hu SJ (2017) Changes of cecal microflora in chickens following Eimeria tenella challenge and regulating effect of coated sodium butyrate. Exp Parasitol 177:73-81

39. Park SK, Kim MS, Roh SW, Bae JW (2012) Blautia stercoris sp nov., isolated from human faeces. Int J Syst Evol Micr 62:776-779

40. Liu C, Finegold SM, Song Y, Lawson PA (2008) Reclassification of Clostridium coccoides, Ruminococcus hansenii, Ruminococcus hydrogenotrophicus, Ruminococcus /uti, Ruminococcus productus and Ruminococcus schinkii as Blautia coccoides gen. nov., comb. nov., Blautia hansenii comb. nov., Blautia hydrogenotrophica comb. nov., Blautia luti comb. nov., Blautia producta comb. nov., Blautia schinkii comb. nov and description of Blautia wexlerae sp nov., isolated from human faeces. Int J Syst Evol Micr 58:1896-1902

41. Sokol H, Jegou S, McQuitty C, Straub M, Leducq V, Landman C, Kirchgesner J, Le Gall G, Bourrier A, Nion-Larmurier I, Cosnes J, Seksik P, Richard $M L$, Beaugerie $L$ (2018) Specificities of the intestinal microbiota in patients with inflammatory bowel disease and Clostridium difficile infection. Gut Microbes 9:55-60

42. Holmstrom K, Collins MD, Moller T, Falsen E, Lawson PA (2004) Subdoligranulum variable gen. nov., sp nov from human feces. Anaerobe 10:197-203

43. Ciorba MA (2012) A gastroenterologist's guide to probiotics. Clin Gastroenterol Hepatol 10:960-968

44. Huang C, Song PX, Fan PX, Hou CL, Thacker P, Ma X (2015) Dietary sodium butyrate decreases postweaning diarrhea by modulating intestinal permeability and changing the bacterial communities in weaned piglets. J Nutr 145:2774-2780

45. Wu W, Xiao ZB, An WY, Dong YY, Zhang BK (2018) Dietary sodium butyrate improves intestinal development and function by modulating the microbial community in broilers. PLoS One 13:e0197762

46. De Boever P, Wouters R, Verschaeve L, Berckmans P, Schoeters G, Verstraete W (2000) Protective effect of the bile salt hydrolase-active Lactobacillus reuteri against bile salt cytotoxicity. Appl Microbiol Biotechnol 53:709-714

47. Dhariwal A, Chong J, Habib S, King IL, Agellon LB, Xia JG (2017) MicrobiomeAnalyst: a web-based tool for comprehensive statistical, visual and meta-analysis of microbiome data. Nucleic Acids Res 45:W180-W188

\section{Publisher's Note}

Springer Nature remains neutral with regard to jurisdictional claims in published maps and institutional affiliations.
Ready to submit your research? Choose BMC and benefit from:

- fast, convenient online submission

- thorough peer review by experienced researchers in your field

- rapid publication on acceptance

- support for research data, including large and complex data types

- gold Open Access which fosters wider collaboration and increased citations

- maximum visibility for your research: over $100 \mathrm{M}$ website views per year

At BMC, research is always in progress.

Learn more biomedcentral.com/submissions 